\title{
Determination of wavelength and Peak position Peak Position in Advanced Materials
}

\author{
Dr. Srivani Alla ${ }^{1}$, Dr. A Raghavendra ${ }^{2}$, O. Sreedevi³, Dr. Y. Bhaskar Rao ${ }^{4}$, \\ Dr. P Vijaya lakshmi ${ }^{5}$ \\ ${ }^{1}$ Vasireddy Venkatadri Institute of Technology, Andhra Pradesh \\ ${ }^{2}$ Mallareddy Engineering College, Telangana \\ ${ }^{3}$ APJ Abdul kalam University, Indore(M.P.)-452016, India \\ ${ }^{4}$ Tirumala Engineering College, Andhra Pradesh \\ ${ }^{5}$ Gudlavelluru Engineering College, Andhra pradesh
}

\begin{abstract}
X-beam powder diffraction is most generally utilized for the distinguishing proof of obscure glasslike materials. Assurance of obscure solids is basic to studies in topography, ecological science, material science, designing and science. Different applications include: portrayal of translucent materials recognizable proof of fine-grained minerals, for example, dirts and blended layer muds that are hard to decide optically assurance of unit cell aspects estimation of test virtue With particular strategies, XRD can be utilized to: decide precious stone constructions utilizing Rietveld refinement decide of modular measures of minerals (quantitative investigation) describe flimsy movies tests by: deciding cross section crisscross among film and substrate and to inducing anxiety deciding disengagement thickness and nature of the film by shaking bend estimations estimating super lattices in complex epitaxial structures. Deciding the thickness, unpleasantness and thickness of the film utilizing looking occurrence X-beam reflectivity estimations make textural estimations, like the direction of grains, in a polycrystalline example.
\end{abstract}

Keyword's: XRD Peak position, Advanced Materials, Inter Atomic Distance.

\section{INTRODUCTION:}

Progressed materials are the premise of current science and innovation. This procedures volume presents a wide range of investigations of novel materials covering their handling strategies, physical science, mechanics, and applications. The book is focused on nanostructures, ferroelectric gems, materials and composites, materials for sunlight based cells and furthermore polymeric composites.

Nanotechnology draws near, current piezoelectric strategies and furthermore most recent accomplishments in materials science, dense matter physical science, mechanics of deformable solids and mathematical techniques are introduced. Extraordinary consideration is committed to novel gadgets with high exactness, life span and stretched out potential outcomes to work in wide temperature and tension territories, forceful media and so on The attributes of materials and composites with further developed properties opening additional opportunities of different actual cycles, specifically transmission and receipt of signs submerged, are portrayed.

Silicon based parts are the core of the present electronic gadgets. The extemporization and improvement of gadgets in view of silicon parts are arriving at furthest cutoff points as far as edge in plan intricacy, power needed for handling, utilization of energy, memory and hotness dispersal through heat sinks.

This has prompted a journey for new materials. One such stream of materials called chalcogenide glasses involving at least one chalcogens as a constituent component display entrancing properties and observe applications is differed spaces. These materials are shapeless semiconductors and are utilized in the present electronic, optical and optoelectronic gadgets like waveguides, biosensors, Phase Change Memory (PCM) which is a sort of Non-Volatile RAM, planar optics and in acknowledging photonic incorporated circuits. 
International Advanced Research Journal in Science, Engineering and Technology

Impact Factor $7.105 \div$ Vol. 9, Issue 1, January 2022

DOI: 10.17148/IARJSET.2022.9151

RESULTS AND DISCUSSION:

\begin{tabular}{|c|c|c|c|}
\hline Sl.No & $\begin{array}{c}\text { Distance between } \\
\text { Bright Spots } \\
(1 / \mathrm{nm})\end{array}$ & $\begin{array}{c}\text { Inter Atomic } \\
\text { distance(d) } \\
\text { Nm }\end{array}$ & XRD Peak Position(20) \\
\hline 1 & 1.1 & 1.82 & 4.9 \\
2 & 1.2 & 1.67 & 5.3 \\
3 & 1.3 & 1.54 & 5.7 \\
4 & 1.4 & 1.43 & 6.2 \\
5 & 1.5 & 1.33 & 6.6 \\
\hline
\end{tabular}

\begin{tabular}{|c|c|c|c|}
\hline Sl.No & $\begin{array}{c}\text { Distance between } \\
\text { Bright Spots }(1 / \mathrm{nm})\end{array}$ & $\begin{array}{c}\text { Inter Atomic distance(d) } \\
\mathrm{nm}\end{array}$ & XRD Peak Position(20) \\
\hline 1 & 1.6 & 1.25 & 7.1 \\
2 & 1.7 & 1.18 & 7.5 \\
3 & 1.8 & 1.11 & 7.9 \\
4 & 1.9 & 1.05 & 8.4 \\
5 & 2.0 & 1.00 & 8.8 \\
\hline
\end{tabular}

\begin{tabular}{|c|c|c|c|}
\hline Sl.No & $\begin{array}{c}\text { Distance between } \\
\text { Bright Spots (1/nm) }\end{array}$ & $\begin{array}{c}\text { Inter Atomic distance(d) } \\
\mathrm{nm}\end{array}$ & XRD Peak Position(20) \\
\hline 1 & 2.1 & 0.95 & 9.3 \\
2 & 2.2 & 0.91 & 9.7 \\
3 & 2.3 & 0.87 & 10.2 \\
4 & 2.4 & 0.83 & 10.6 \\
5 & 2.5 & 0.80 & 11.0 \\
\hline
\end{tabular}

\begin{tabular}{|c|c|c|c|}
\hline S1.No & $\begin{array}{c}\text { Distance between Bright } \\
\text { Spots }(1 / \mathrm{nm})\end{array}$ & $\begin{array}{c}\text { Inter Atomic distance(d) } \\
\mathrm{Nm}\end{array}$ & XRD Peak Position(20) \\
\hline 1 & 3.1 & 0.65 & 13.7 \\
2 & 3.2 & 0.63 & 14.1 \\
3 & 3.3 & 0.61 & 14.6 \\
4 & 3.4 & 0.59 & 15.0 \\
5 & 3.5 & 0.57 & 15.5 \\
\hline
\end{tabular}

\begin{tabular}{|c|c|c|c|}
\hline Sl.No & $\begin{array}{c}\text { Distance between } \\
\text { Bright Spots }(1 / \mathrm{nm})\end{array}$ & $\begin{array}{l}\text { Inter Atomic distance(d) } \\
\mathrm{nm}\end{array}$ & XRD Peak Position(2 2 ) \\
\hline 1 & 3.6 & 0.56 & 15.9 \\
\hline 2 & 3.7 & 0.54 & 16.3 \\
\hline 3 & 3.8 & 0.53 & 16.8 \\
\hline 4 & 3.9 & 0.51 & 17.2 \\
\hline 5 & 4.0 & 0.50 & 17.7 \\
\hline
\end{tabular}


International Advanced Research Journal in Science, Engineering and Technology

Impact Factor $7.105 \div$ Vol. 9, Issue 1, January 2022

DOI: $10.17148 /$ IARJSET.2022.9151

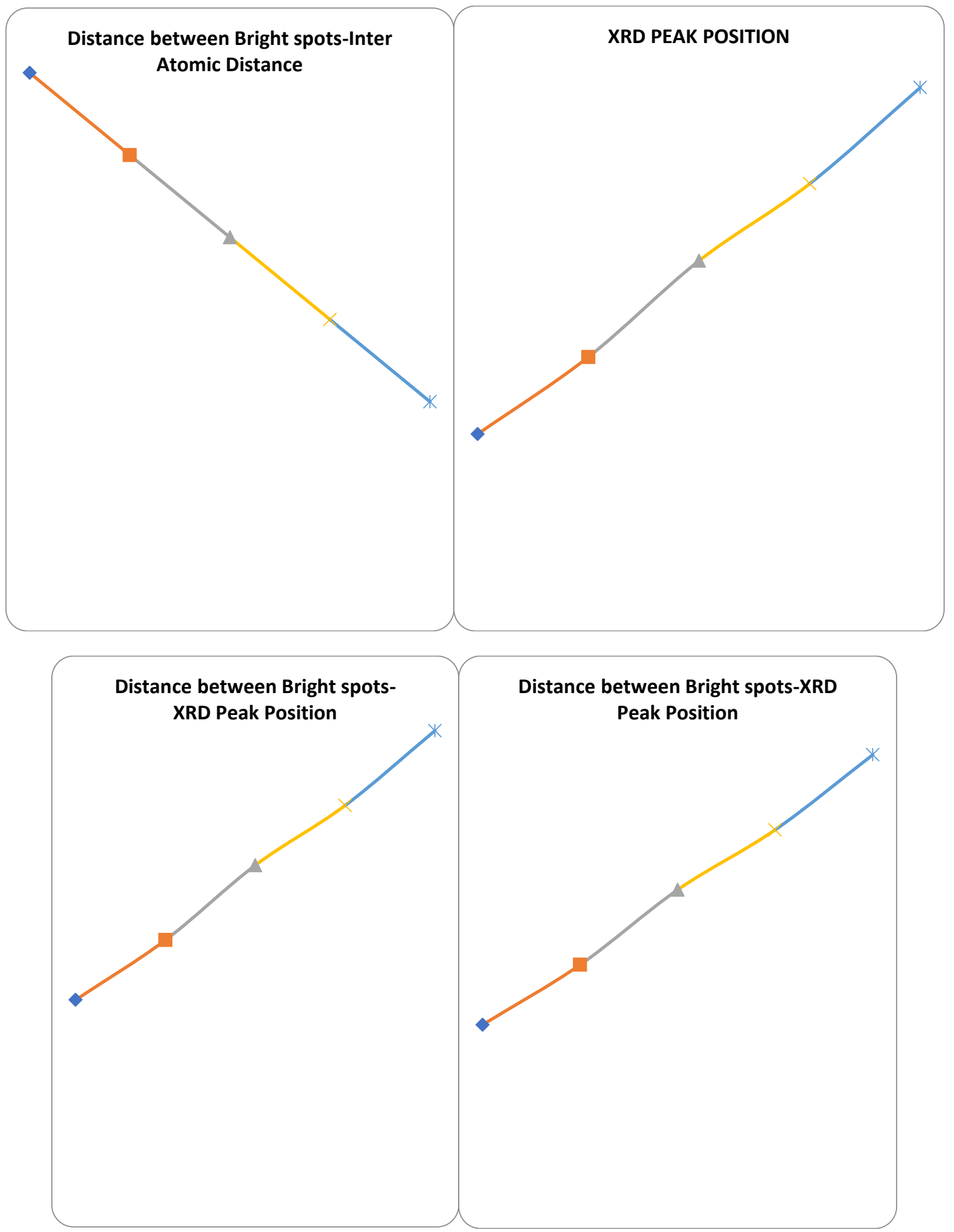

CONCLUSION:

The area of cutting edge materials research is very expansive in its degree and has various expected applications. While a few progressed materials are now all around reported, it will require a couple of more years for others to show up in items available. Anyway, what precisely are progressed materials? This exclusive class of materials incorporates metals, earthenware production, gels, polymers and composites. The main element of a high level material, be that as it may, is its vital job in item plan. It upgrades part execution and, in this manner, upgrades whole frameworks, considering a more conservative plan, with further developed eco-friendliness, and more prominent generally solidness. 


\section{International Advanced Research Journal in Science, Engineering and Technology \\ Impact Factor $7.105 \div$ Vol. 9, Issue 1, January 2022 \\ DOI: $10.17148 /$ IARJSET.2022.9151}

One such progressed material is the shape memory compound, which is an amalgam that recollects its structure, and can be gotten back to that figure in the wake of being distorted, by the use of hotness to the combination. At the point when the shape memory impact is accurately bridled, this material turns into a lightweight, strong state option in contrast to regular actuators, for example, water driven, pneumatic, and engine based frameworks. Consequently, shape memory combinations, otherwise called shrewd amalgams, have various applications in areas like the clinical and aviation businesses. They are likewise amazingly powerful as warm sensors and actuators in wide-going applications, as heated water pots, forced air systems and autos. These metals are additionally utilized in electrically activated fake muscles for automated hands and careful endoscopes. Besides, biomedical embeds likewise benefit from the material's capacity to get back to a foreordained shape. For instance, constructions can be disfigured so they can enter the body by means of keyhole medical procedure and afterward be extended through body heat.

Progressed materials innovations are significant benefactors in many worth chains serving driving edge applications. The European commission has perceived this reality and they have remembered progressed materials for the rundown of six innovation areas that are relied upon to empower, defend and animate future modern movement in the European Union. A huge piece of our future labor and products are at this point obscure, however the vitally main thrust behind their improvement will be key empowering advances (KETs), like nanotechnology, miniature and nanoelectronics, including semiconductors, progressed materials, biotechnology and photonics.

"KETs are the vital 'innovation blocks' to fabricate a wide scope of item applications to lead the mechanical jump forward for serious progressed modern creation, regardless of whether it is the electric vehicle, satellites, clinical gadgets or progressed buyer merchandise", said a representative for the European commission. Dominating these advances will guarantee that the EU stays at the front line of dealing with the shift to a low carbon, information based economy. They assume a significant part in the innovative work, development and bunch systems of numerous enterprises and are viewed as vital for guaranteeing the intensity of European businesses in the information economy.

Progressed materials research includes disclosures of the crucial standards of science, math and physical science that can be applied to control the properties of new materials, and afterward forming materials or nanostructures for genuine applications. It includes knowing the conditions under which a material will be utilized and distinguishing competitor materials for this reason. There is generally a genuine requirement for better materials, the genuine inquiry, in any case, is how much better and at what cost?

\section{REFERENCES:}

1. Martin Mitterböck,, Gerhard Fleissner,, Andreas Hallbrucker, and, Erwin Mayer. Anomalous Contact-Ion Pairing in the Glassy States of "Dilute" Aqueous Lithium and Sodium Perchlorate Solution. The Journal of Physical Chemistry B 1999, 103 (37) , 8016-8025. https://doi.org/10.1021/jp991399k

2. William R. Hruschka, David R. Massie, and James D. Anderson. Computerized analysis of two-dimensional electrophoretograms. Analytical Chemistry 1983, 55 (14) , 2345-2348. https://doi.org/10.1021/ac00264a033

3. Tao Chin Lin. Wang and Alan G. Marshall. Plots of dispersion vs. absorption for detection of multiple positions or widths of Gaussian spectral signals. Analytical Chemistry 1983, 55 (14) , 23482353. https://doi.org/10.1021/ac00264a034

4. Andrew. Proctor and Peter M. A. Sherwood. Data analysis techniques in x-ray photoelectron spectroscopy. Analytical Chemistry 1982, 54 (1) , 13-19. https://doi.org/10.1021/ac00238a008

5. P. A. Boudreau and S. P. Perone. Quantitative resolution of overlapped peaks in programmed potential-step voltammetry. Analytical Chemistry 1979, 51 (7), 811-817. https://doi.org/10.1021/ac50043a009

6. B. G. M. Vandeginste and L. De Galan. Critical evaluation of curve fitting in infrared spectrometry. Analytical Chemistry 1975, 47 (13) , 2124-2132. https://doi.org/10.1021/ac60363a029

7. Bruce M. Golden and Edward S. Yeung. Analytical lines for long-path infrared absorption spectrometry of air pollutants. Analytical Chemistry 1975, 47 (13), 2132-2135. https://doi.org/10.1021/ac60363a047

8. B. E. Barker, M. F. Fox, E. Hayon, and E. W. Ross. Simple digital method for resolving overlapping electronic absorption bands. Analytical Chemistry 1974, 46 (12), 1785-1789. https://doi.org/10.1021/ac60348a006

9. M. Zamir-ul. Haq, Samie J. Rose, Lisa R. Deiderich, and Appasaheb R. Patel. Identification and quantitative measurement of some N-heterocyclics in marijuana smoke condensates. Analytical Chemistry 1974, 46 (12) , 17811785. https://doi.org/10.1021/ac60348a057

10. Geert. Brouwer and J. A. J. Jansen. Deconvolution method for identification of peaks in digitized spectra. Analytical Chemistry 1973, 45 (13), 2239-2247. https://doi.org/10.1021/ac60335a001 